\title{
RESEARCH
}

Open Access

\section{Establishment of a rapid and footprint-free protocol for differentiation of human embryonic stem cells into pancreatic endocrine cells with synthetic mRNAs encoding transcription factors}

Hideomi Ida ${ }^{1,2}$, Tomohiko Akiyama', Keiichiro Ishiguro', Sravan K. Goparaju', Yuhki Nakatake, Nana Chikazawa-Nohtomi ${ }^{1}$, Saeko Sato ${ }^{1}$, Hiromi Kimura', Yukihiro Yokoyama², Masato Nagino², Minoru S. H. Ko and Shigeru B. H. Ko ${ }^{1 *}$

\begin{abstract}
Background: Transplantation of pancreatic $\beta$ cells generated in vitro from pluripotent stem cells (hPSCs) such as embryonic stem cells (ESCs) or induced pluripotent stem cells (iPSCs) has been proposed as an alternative therapy for diabetes. Though many differentiation protocols have been developed for this purpose, lentivirus-mediated forced expression of transcription factors (TF) - PDX1 and NKX6.1 - has been at the forefront for its relatively fast and straightforward approach. However, considering that such cells will be used for therapeutic purposes in the future, it is desirable to develop a procedure that does not leave any footprint on the genome, as any changes of DNAs could potentially be a source of unintended, concerning effects such as tumorigenicity. In this study, we attempted to establish a novel protocol for rapid and footprint-free hESC differentiation into a pancreatic endocrine lineage by using synthetic mRNAs (synRNAs) encoding PDX1 and NKX6.1. We also tested whether siPOU5F1, which reduces the expression of pluripotency gene POU5F1 (also known as OCT4), can enhance differentiation as reported previously for mesoderm and endoderm lineages.
\end{abstract}

Methods: synRNA-PDX1 and synRNA-NKX6.1 were synthesized in vitro and were transfected five times to hESCs with a lipofection reagent in a modified differentiation culture condition. siPOU5F1 was included only in the first transfection. Subsequently, cells were seeded onto a low attachment plate and aggregated by an orbital shaker. At day 13 , the degree of differentiation was assessed by quantitative RT-PCR (qRT-PCR) and immunohistochemistry for endocrine hormones such as insulin, glucagon, and somatostatin.

Results: Both PDX1 and NKX6.1 expression were detected in cells co-transfected with synRNA-PDX1 and synRNANKX6.1 at day 3. Expression levels of insulin in the transfected cells at day 13 were 450 times and 14 times higher by qRT-PCR compared to the levels at day 0 and in cells cultured without synRNA transfection, respectively. Immunohistochemically, pancreatic endocrine hormones were not detected in cells cultured without synRNA transfection but were highly expressed in cells transfected with synRNA-PDX1, synRNA-NKX6.1, and siPOU5F1 at as early as day 13.

(Continued on next page)

\footnotetext{
* Correspondence: kos@keio.jp

${ }^{1}$ Department of Systems Medicine, Keio University School of Medicine, 35

Shinanomachi, Shinjuku, Tokyo 160-8582, Japan

Full list of author information is available at the end of the article
}

(c) The Author(s). 2018 Open Access This article is distributed under the terms of the Creative Commons Attribution 4.0 International License (http://creativecommons.org/licenses/by/4.0/), which permits unrestricted use, distribution, and reproduction in any medium, provided you give appropriate credit to the original author(s) and the source, provide a link to the Creative Commons license, and indicate if changes were made. The Creative Commons Public Domain Dedication waiver (http://creativecommons.org/publicdomain/zero/1.0/) applies to the data made available in this article, unless otherwise stated. 
(Continued from previous page)

Conclusions: In this study, we report a novel protocol for rapid and footprint-free differentiation of hESCs to endocrine cells.

Keywords: Embryonic stem cells, Endocrine differentiation, Transcription factors, Synthetic mRNAs, Pancreatic $\beta$ cells, PDX1, NKX6.1, siPOU5F1

\section{Background}

Type 1 diabetes mellitus (T1DM) is an endocrine disorder that is characterized by autoimmune destruction of insulin-producing $\beta$ cells. To treat T1DM patients, the primary therapy is injections of exogenous insulin to control their blood glucose levels throughout their lives. However, they often suffer from diabetic complications such as cardiovascular or cerebrovascular disturbance, retinopathy, kidney failure, and neuropathy that lead to an impaired quality of life. An alternative therapy is homologous pancreatic islet transplantation. However, the application of this therapy is limited because of the shortage of donor islets and the requirement of lifelong immunosuppression therapy after transplantation. To overcome these obstacles, the use of pancreatic $\beta$ cells differentiated in vitro from human embryonic stem cells (ESCs) or induced pluripotent stem cells (iPSCs) has been proposed [1-7]. However, these differentiation protocols require a rather long period of time and complicated culture steps, posing further challenges for their clinical application.

PDX1 and NKX6.1 are well-known transcription factors (TFs) for endocrine cell development. PDX1 (pancreatic and duodenal homeobox-1) is expressed in foregut endoderm and plays a pivotal role in the differentiation of all pancreatic cell types, because the entire pancreas is absent in PDX1 knockout mice at birth [8]. NKX6.1 (NK6 homeobox-1) is expressed in pancreatic endoderm and endocrine precursor cells and is essential for $\beta$ cell identity, controlling cell lineages between endocrine and acinar cell fate [9-11]. It has also been demonstrated that iPSCs can be differentiated into mature insulin-producing cells by lentivirus-mediated overexpression of PDX1 and NKX6.1 using the Tet-On System combined with endocrine differentiation medium [12]. This study showed that PDX1 and NKX6.1 are crucial factors for differentiating hPSCs into insulin-producing endocrine cells.

Previously, we have reported a novel differentiation method for hESCs and hiPSCs into neuronal cells [13], skeletal muscle cells [14], and epithelial cells [15] by introducing synthetic mRNAs (synRNAs) encoding transcription factors specific to the targeted differentiated cells. Differentiation by synRNAs holds many desirable features for further clinical application, because it allows rapid, efficient, and footprint-free differentiation of human pluripotent stem cells [16]. We have also reported that the forced silencing of pluripotency master regulator POU5F1 (also known as OCT4, OCT3/4) by siPOU5F1 facilitates synRNA-based hPSC differentiation [17].

In this study, we aimed to establish a rapid, footprint-free, and simpler differentiation protocol for hESCs into pancreatic endocrine cells, especially insulin-producing $\beta$ cell-like cells, by the combined introduction of synRNAs encoding PDX1, NKX6.1, and SiPOU5F1.

\section{Methods}

\section{Cells and culture media}

SEES-3 human ES cells were obtained from the National Center for Child Health and Development, Japan [18], and cultured under feeder-free conditions in StemFit AK02N medium (Ajinomoto, Tokyo, Japan) on laminin511 E8 fragment (iMatrix-511: Nippi, Tokyo, Japan)-coated dishes. All experiments were performed in accordance with the Guidelines for Derivation and Utilization of $\mathrm{Hu}$ man Embryonic Stem Cells by the Ministry of Education, Culture, Sports, Science, and Technology, Japan. Experimental protocols were approved by the Ethics Committee of Keio University School of Medicine for human stem cell experiments (No. 2012-01) and for recombinant DNA experiments (No. 24-010-12).

\section{Modified RNA synthesis and siRNA}

The open reading frames for PDX1 and NKX6.1 were subcloned into a pCRII construct containing the $5^{\prime}$ and 3' untranslated regions of mouse alpha-globin to prepare the templates used for synthesizing the mRNAs. The modified mRNAs were produced as described previously [19]. siPOU5F1 (silencer Select ID s10873) was obtained from Life Technologies.

\section{In vitro differentiation of human ES cells}

SEES-3 human ES cells were seeded and cultured on 24-well plates coated with 1:30 diluted Matrigel (Corning, $\mathrm{NY}$ ) at a density of $8.0 \times 10^{4}$ cells per well in StemFit AK02N medium with $10 \mu \mathrm{M}$ Y-27632 (WAKO, Japan) for 2 days. At $\sim 80 \%$ confluency, PDX1 and NKX6.1 synthetic -mRNA (synRNA) introduction was started. mRNAs encoding these transcription factors were transfected with Lipofectamine MessengerMax Transfection Reagent (Thermo Fisher Scientific, MA) every $12 \mathrm{~h}$ (total of five times) according to the manufacturer's instructions. For POU5F1 silencing, siPOU5F1 was transfected 
once and was included only in the first cocktail of PDX1 and NKX6.1 mRNA transfection. A total of $1 \mu \mathrm{g}$ mRNA in opti-MEM-reduced serum media (Thermo Fisher Scientific) was mixed with $2 \mu$ l MessengerMax Reagent in Opti-MEM media and incubated for $5 \mathrm{~min}$ at room temperature. B18R interferon inhibitor (eBioscience) was included in the transfection complex to inhibit the interferon response caused by mRNA introduction to the cells. The differentiation medium was replaced $3 \mathrm{~h}$ after every transfection.

We replaced the differentiation medium every $12 \mathrm{~h}$ for 3 days; the process is described as $\mathrm{d} X$-a (first medium change on day $X$ ) to $\mathrm{d} X$-b (second medium change on day $X)$. The differentiation conditions used were as follows: d0-a: RPMI 1640 medium (Thermo Fisher Scientific) supplemented with 1:100 B27 (Thermo Fisher Scientific), 1:5000 ITS (Thermo Fisher Scientific), $100 \mathrm{ng} / \mathrm{ml}$ activin A (R\&D Systems, MN), and rhWNT3a (R\&D Systems, MN); d0-b: RPMI 1640 medium supplemented with 1:100 B27, 1:2000 ITS, and $100 \mathrm{ng} / \mathrm{ml}$ activin A; d1-a: RPMI 1640 medium supplemented with 1:100 B27, 1:1000 ITS, $2.5 \mu \mathrm{M}$ TGFbi IV (Merck KGaA, Germany), and $25 \mathrm{ng} / \mathrm{ml}$ KGF (PeproTech, NJ); d1-b: RPMI 1640 medium supplemented with 1:100 B27, 1:1000 ITS, and 25 ng/ml KGF; d2-a: DMEM (nacalai tesque, Japan) with $25 \mathrm{mM}$ glucose supplemented with 1:100 B27 and 3 nM TTNBP (Sigma-Aldrich, Germany); d2-b: DMEM with $25 \mathrm{mM}$ glucose supplemented with 1:100 B27, $50 \mathrm{ng} / \mathrm{ml}$ EGF (PeproTech), $50 \mathrm{ng} / \mathrm{ml} \mathrm{KGF,} \mathrm{and} 3 \mathrm{nM}$ TTNBP. Twelve hours after the last transfection, cells were dissociated into single cells by incubation with TrypLE (Thermo Fisher Scientific). Cells were counted and seeded on 24-well low-binding plates at a density of $1.6 \times 10^{5}$ cells per well in $500 \mu \mathrm{l} \mathrm{d} 3-7$ medium supplemented with $10 \mu \mathrm{m}$ Y-27632 and $10 \mathrm{ng} / \mathrm{ml}$ heregulin-b1(PeproTech). Plates were placed on an orbital shaker at $100 \mathrm{rpm}$ for the rest of the culture period, d3-7: DMEM with $25 \mathrm{mM}$ glucose supplemented with 1:100 B27, 500 nM LDN193189 (Stemgent, MA), 3 nM TBP (Calbiochem), $1000 \mathrm{nM}$ ALKi II (Cayman Chemical, MI), and $25 \mathrm{ng} / \mathrm{ml}$ KGF. From days 3 to 7 , medium was replaced every 2 days by removing $250 \mu \mathrm{l}$ of medium and adding fresh $250 \mu \mathrm{l}$ of medium. After culturing for 5 days, the medium was then changed to d8-12 medium, d8-12: DMEM with $2.8 \mathrm{mM}$ glucose supplemented with 1:100 Glutamax (Gibco) and 1:100 NEAA (nacalai tesque).

\section{Immunocytochemistry}

After removing the culture medium, cells were rinsed with PBS once and fixed with $4 \%$ paraformaldehyde (Wako, Japan) for $10 \mathrm{~min}$ at room temperature and blocked with $0.3 \%$ Triton-X-100 (Sigma-Aldrich, Germany) and 5\% BSA in PBS for $30 \mathrm{~min}$ at room temperature. The fixed cells were then incubated with primary antibodies overnight at $4{ }^{\circ} \mathrm{C}$. The primary antibodies used were as follows: goat anti-PDX1 (1:100; R\&D Systems, AF2419), mouse anti-NKX6.1 (1:50; DSHB, F55A10-s), goat anti-FOXA2 (1:100; R\&D Systems, AF2 400), mouse anti-HNF1B (1:100; Sigma-Aldrich, HPA00 2083), goat anti-HNF4A (1:100; Santa Cruz, sc-6556), rabbit anti-HNF6 (1:100; Santa Cruz, sc-13050), and mouse anti-NEUROD1 (1:100; Abcam, ab60704). After washing with PBS three times, cells were incubated for 60 to $120 \mathrm{~min}$ at room temperature with Alexa Fluor conjugated secondary antibodies (1:1000; Life Technologies). After washing with PBS twice, DAPI (1:1000; Life Technologies) with PBS was added to stain the nucleus. Images were captured using an Olympus microscope IX73.

\section{Immunocytochemistry for cryosections}

After washing with PBS once, cell clusters were fixed with $4 \%$ paraformaldehyde (PFA) overnight at $4{ }^{\circ} \mathrm{C}$. Following fixation, PFA was removed and cells were washed three times with PBS for 5 min each and equilibrated in 30\% sucrose solution overnight at $4{ }^{\circ} \mathrm{C}$. The cells were overlaid with OCT Compound and frozen using liquid nitrogen. The frozen blocks were sectioned at $10 \mu \mathrm{m}$. The sections were washed with PBS twice for 5 min each and blocked with $0.3 \%$ Triton-X-100 and 5\% BSA in PBS for $1 \mathrm{~h}$ at room temperature. Primary antibodies were added overnight at $4{ }^{\circ} \mathrm{C}$ in a blocking buffer. After washing with PBS three times for $5 \mathrm{~min}$, secondary antibodies were added for $30 \mathrm{~min}$ at room temperature in a blocking buffer. After washing with PBS three times for $5 \mathrm{~min}$, sections were mounted with VECTASHIELD Mounting Medium with DAPI (Vector Laboratories) on glass slides.

\section{Quantitative RT-PCR}

Total RNA was extracted from cells using TRIzol Reagent (Thermo Fisher Scientific) and Direct-Zol RNA Miniprep (ZYMO RESEARCH) according to the manufacturer's instructions. Quantitative RT-PCR (qRT-PCR) was performed using SYBR Fast qPCR Mix (Takara Bio, Japan) and Thermal Cycler Dice Real Time System III (Takara Bio). The Ct values and relative expression levels were normalized by glyceraldehyde-3-phosphate dehydrogenase (GAPDH) levels.

\section{Statistical analysis}

The difference between samples was compared by the two-tailed Student's $t$ test and statistical significance was considered as $p<0.05$. All data were presented as mean \pm SEM (standard error of the mean).

\section{Results}

\section{Production and test of synRNAs}

Generation of synthetic mRNA (synRNAs) was performed as reported previously (Fig. 1a) [13]. To evaluate 


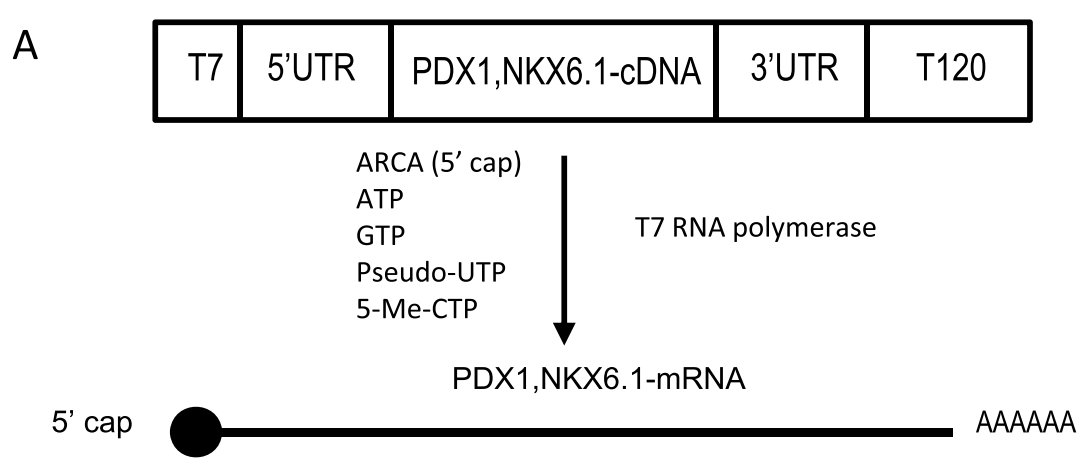

B

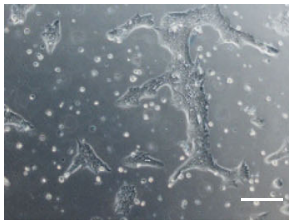

DIC

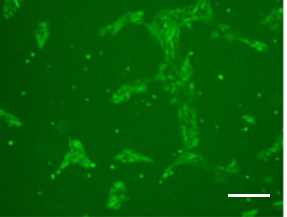

Emerald

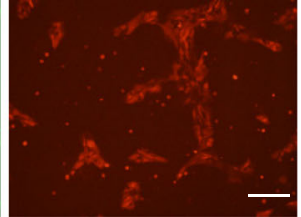

Cherry

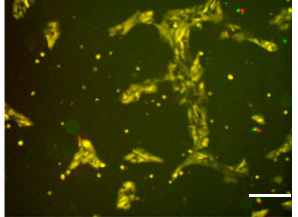

Merge

Fig. 1 The efficiency of synthetic mRNA transfection of PDX1 and NKX6.1 into SEES3 human ESCs. a Generation of synthetic messenger RNAs. ARCA: anti-reverse cap analog, pseudo-UTP: pseudouridine-5'-triphosphate, 5-Me-CTP: 5-methyl cytidine-5'-triphosphate. b Expression of synthetic messenger RNA for fluorescent proteins Emerald and mCherry in SEES3 human ESCs. Scale bars, $200 \mu \mathrm{m}$

the co-transfection efficiency of synRNAs to hESCs, we co-transfected synRNAs encoding green fluorescence protein variants-Emerald (green) and mCherry (red)and monitored the protein expression by microscopy $8 \mathrm{~h}$ after transfection. Each fluorescent protein was efficiently expressed and the expressions of two proteins were clearly merged in most cells (Fig. 1b). This result confirmed the high efficiency of the synRNA-based protein expression in hESCs.

\section{Generation of $\mathrm{PDX} 1^{+} / \mathrm{NKX} 6.1^{+}$pancreatic endoderm/ endocrine precursor cells}

As a first step to establish a differentiation protocol, we started with the protocol reported by Russ et al. [3], because their method is simple and rapid compared with other protocols for the differentiation of hPSCs into insulin-producing cells. We noticed that the protocol takes 7-9 days until PDX1 ${ }^{+}$or $\mathrm{PDX}^{+} / \mathrm{NKX} 61^{+}$cells appear, and additional 3 weeks until insulin ${ }^{+} \beta$-like cells appear. Therefore, we first focused on generating PDX1and NKX6.1-positive pancreatic endoderm cells by exogenously introducing synRNA-PDX1 and synRNA-NKX6.1 together with siPOU5F1 with their pancreatic endocrine differentiating conditions (Fig. 2a).

We analyzed the expression levels of PDX1 and NKX6.1 by qRT-PCR after five transfections and compared the results with those of day 0 (D 0 ) that is a cellular state of undifferentiated ES cells and cells treated with differentiation medium alone (no transfection). Using
PCR-primers detecting both endogenous and exogenous PDX1 and NKX6.1, the expression levels of PDX1 increased 147-fold compared with that of no transfection. The expression of NKX6.1 increased 286-fold compared with that of no transfection (Fig. 2b), indicating that both PDX1 and NKX6.1 were significantly overexpressed in cells transfected with mRNAs encoding these transcription factors as early as at day 3 . Although there was a significant difference in the expression levels between PDX1 and NKX6.1, this result may simply be a reflection of the difference of translation efficiency of PDX1 and NKX6.1 synRNAs in these cells.

Using antibodies against PDX1 and NKX6.1, protein expression was immunocytochemically confirmed: a significant number of $\mathrm{PDX1}^{+} / \mathrm{NKX} 6.1^{+}$cells were present even at day 3 (Fig. 2c). The ratio of $\mathrm{PDX1}^{+}, \mathrm{NKX}^{+} 1^{+}$, and $\mathrm{PDX1}^{+} /$ NKX6. $1^{+}$was $23 \%, 20 \%$, and $16 \%$, respectively. Taken together, these results indicated that hESCs were able to differentiate into pancreatic endoderm cells within 3 days with the aid of synRNA-PDX1, synRNA-NKX6.1, and siPOU5F1.

\section{Endoderm and endocrine precursor cell marker expression}

To examine whether these PDX1 ${ }^{+}$and/or NKX6.1 ${ }^{+}$cells are indeed endoderm or endocrine precursor cells, marker gene expressions were analyzed by qRT-PCR at day 3 just after five consecutive transfections of synRNA-PDX1 and synRNA-NKX6.1 together with siPOU5F1. 


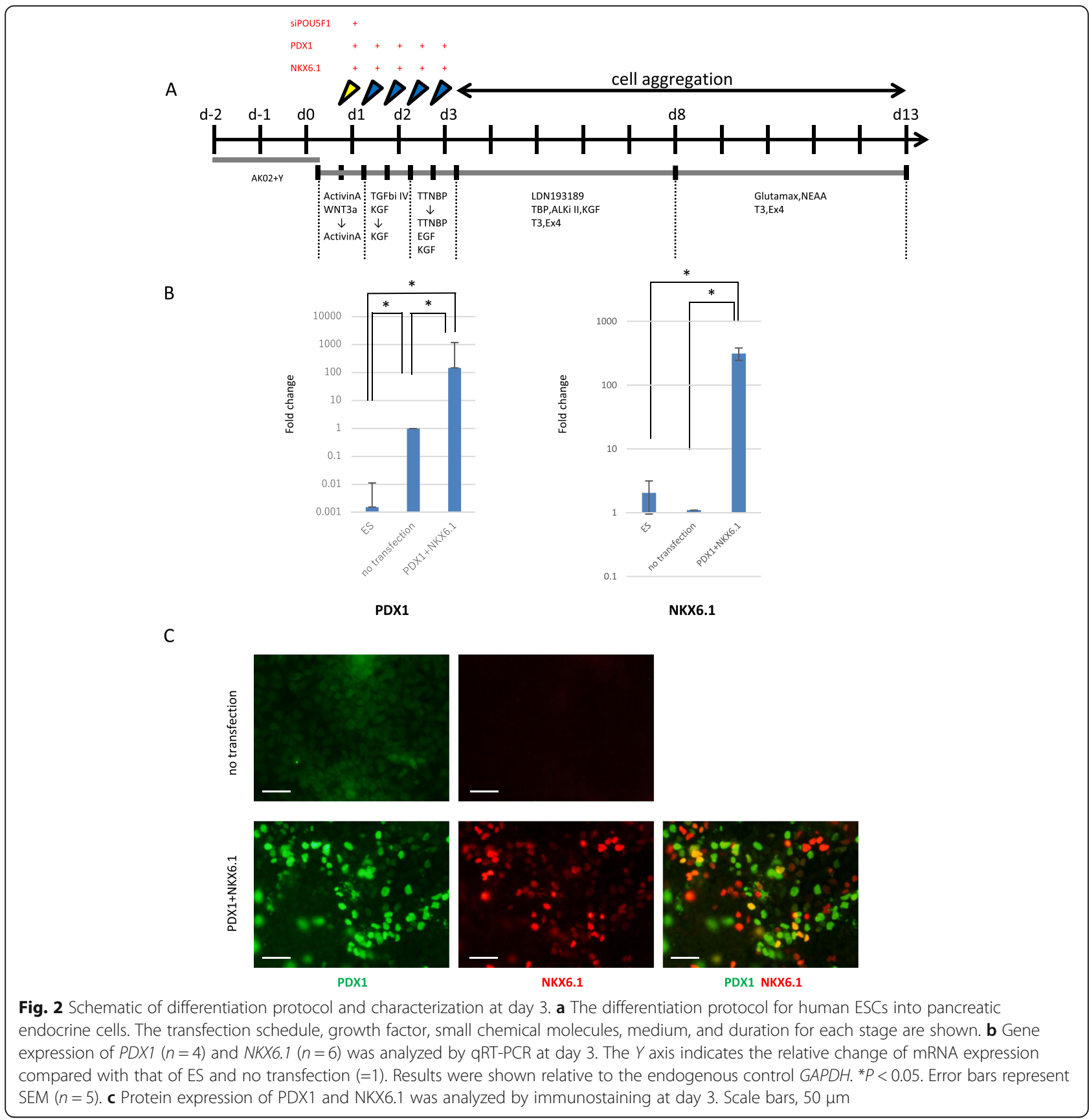

The expression levels of definitive endoderm (DE) markers FOXA2 and SOX17 in cells with synRNA transfection were increased 300- and 4980-fold, respectively, compared with the level in ES cells. Although the expression level of SOX17 showed no difference in cells with no transfection and synRNA-PDX1/synRNA-NKX6.1-transfected, the expression level of FOXA2 in cells transfected with synRNAs was increased significantly compared with the level in cells with no transfection (Fig. 3a). FOXA2 protein expression was detected in cells transfected with synRNA-PDX1/synRNA-NKX6.1 by immunocytochemical analysis. The number of FOXA2-positive cells in cells with no transfection and PDX1/NKX6.1 transfection was 13\% and $94 \%$, respectively (Fig. 3d), indicating that the introduction of synRNA-PDX1/synRNA-NKX6.1 further promotes hESCs' differentiation into DE.

The expression levels of primitive gut tube (PGT) markers HNF1B and HNF4A in cells with synRNA transfection was increased 2.4-fold and 16.5-fold, respectively, compared to cells with no transfection (Fig. 3b). Posterior foregut endoderm (PFE) markerHNF6-was increased 1.5-fold compared with that of no 


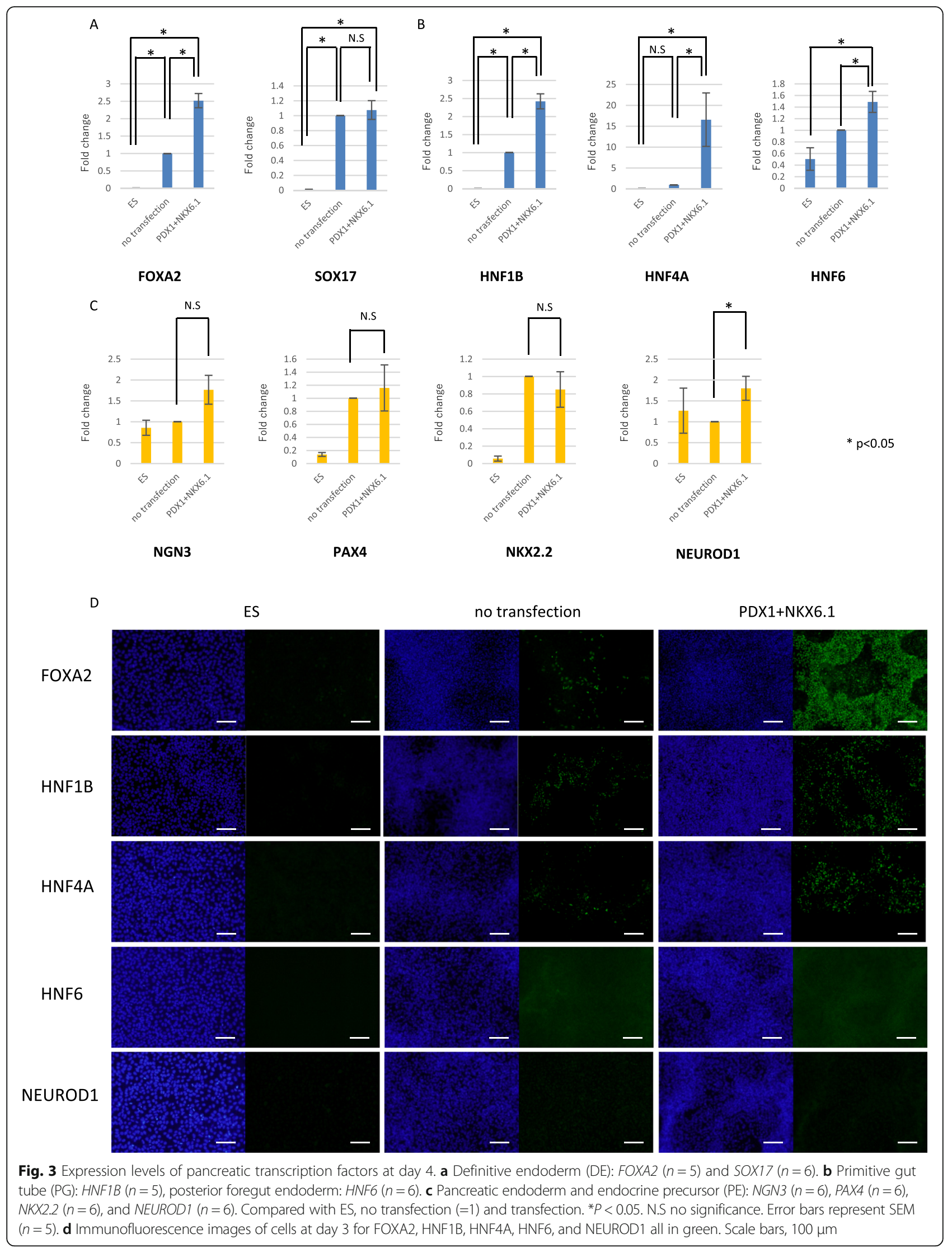




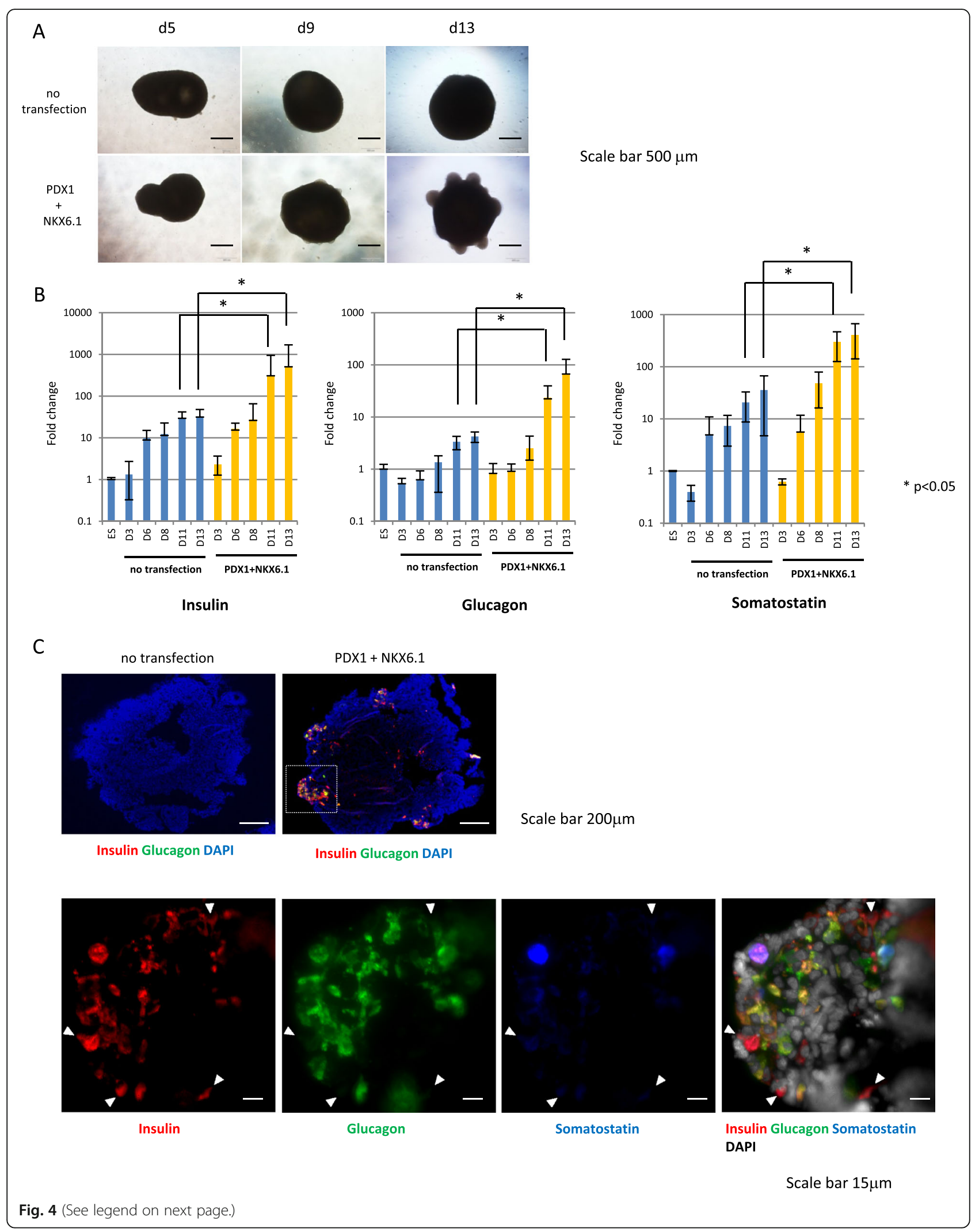


(See figure on previous page.)

Fig. 4 Characterization of pancreatic hormone in human ESC-derived culture at day 13. a Time course culture of non-transfected and transfected cells at days 5, 9, and 13. Scale bars, $500 \mu \mathrm{m}$. b Time course of gene expressions. Insulin, glucagon, and somatostatin were analyzed by qRT-PCR at day 13. The $Y$ axis indicates the relative change of mRNA expression compared with that of no transfection. Results were shown relative to the endogenous control GAPDH. ${ }^{*} P<0.05$. Error bars indicate SEM $n=4$. c Upper panels show insulin (red) and glucagon (green) immunostainings and a DAPI staining (blue) at day 13. Scale bars, $200 \mu \mathrm{m}$. Lower panels show insulin (red), glucagon (green), and somatostatin (blue) immunostainings and a DAPI staining (gray) at day 13. Monohormonal insulin-positive cells: white arrow heads. Scale bars, $15 \mu \mathrm{m}$

transfection. Although the protein expression of HNF6 was not detected, we confirmed HNF4A and HNF1B protein expression in both no transfected cells and synRNA-transfected cells. The number of HNF4A-positive cells in cells with no transfection and synRNA-PDX1/ NKX6.1 transfection was $1.5 \%$ and $14.1 \%$, and the number of HNF1B-positive cells was $28.2 \%$ and $13.4 \%$, respectively (Fig. 3d). These results indicate that the introduction of synRNA-PDX1/synRNA-NKX6.1 further promotes differentiation to PGT/PFE cells.

NEUROGENIN3 (NGN3), PAX4, NKX2.2, and NEUROD1 are markers of endocrine precursor (PE) cells. The expression levels of NGN3, PAX4, and NKX2.2 in cells transfected with synRNA-PDX1/synRNA-NKX6.1 were not increased significantly compared with that of no transfection. The other PE marker, NEUROD1, showed slight increase by qRT-PCR in cells transfected with synRNA-PDX1/synRNA-NKX6.1 compared to the expression levels in cells treated with differentiation medium alone (Fig. 3c), but the protein expression of NEUROD1 was not detected by immunocytochemistry (Fig. 3d). These results may indicate that synRNA-PDX1 and synRNA-NKX6.1 and siPOU5F1 transfection differentiate hESCs to cells in the PGT or PEE stage, but not to pancreatic endocrine precursor cells at day 3 .

\section{$\mathrm{PDX} 1^{+} / \mathrm{NKX} 6.1^{+}$cells further differentiate to pancreatic endocrine cells in three-dimensional culture conditions} Three-dimensional (3D) culture by cell aggregation is known to promote the maturation of cells in the pancreatic endocrine lineage [4]. To further promote differentiation to terminally differentiated insulin-positive $\beta$-like cells, PDX $1^{+} / \mathrm{NKX} 6.1^{+}$cells were aggregated and cultured on an orbital shaker at $100 \mathrm{rpm}$ from days 3 to 13 . A few small buddings were observed at day 5 and cystic structures were observed at day 9 (data not shown) in cell clusters transfected with synRNA-PDX1 and synRNA-NKX6.1 (Fig. 4a, lower panels), but the cell clusters with culture conditions alone showed no morphological changes during the culture period to day 13 (Fig. 4a, upper panels).

To test whether these cells were indeed differentiated into pancreatic endocrine cells, we next examined the expression levels of pancreatic hormones-insulin, glucagon, and somatostatin-by qRT-PCR. In culture conditions alone (no transfection), insulin expression was increased in cells from days 6 to 13 compared with those at day 0 or day 3. In synRNA-transfected cells, insulin expression was significantly increased (approximately tenfold) compared with those in cells with no transfections after days 11 to 13 , indicating that synRNA introduction to cells at days $0-2$ promoted differentiation of cells to pancreatic endocrine cells at days 11-13. Glucagon expression was increased at days 11-13 and somatostatin expression was increased after day 6 in cells with no transfection compared with that of control cells, respectively. The introduction of synRNAs significantly increased glucagon and somatostatin expression (approximately tenfold) compared with cells with no transfection at days 11 and 13 (Fig. 4b). These results clearly indicated that in addition to pancreatic endocrine differentiation culture conditions, the introduction of synRNA-PDX1, synRNA-NKX6.1, and siPOU5F1 to hESCs furthers and efficiently promotes endocrine differentiation.

To confirm the spatial expression pattern of pancreatic endocrine hormones in cell clusters, expression of insulin, glucagon, and somatostatin was immunohistochemically examined. Under pancreatic differentiation culture conditions with no mRNA transfection, expression of insulin and glucagon was not observed at day 13 . However, we confirmed that cells expressing insulin and glucagon appeared in mRNA-transfected cells at day 13 (Fig. 4c). The ratio of the cells expressing insulin, glucagon, and somatostatin was $5.6 \%, 2.6 \%$, and $3.4 \%$, respectively. Notably, there are some monohormonal, insulin-positive, but glucagonand somatostatin-negative cells (Fig. 4c, white arrow head) among pancreatic endocrine hormone-expressing cells with synRNA-PDX1/NKX6.1 transfection.

\section{Discussion}

In this study, we have established a rapid, efficient, and footprint-free protocol of hESC differentiation into pancreatic endocrine cells by introducing synRNA-PDX1 and synRNA-NKX6.1 together with siPOU5F1. By adding these synRNAs, the expression level of insulin-positive cells was increased about ten times compared to cells with no transfection, and insulin-positive cells appeared at as early as day 11 by qRT-PCR and at day 13 by immunohistochemical examinations. With the aid of transcription factor mRNA transfection, we were able to shorten the time required for the differentiation of pancreatic endocrine hormone-expressing cells for human ESCs. 
The definitive endoderm is the first step to induce the differentiation of pancreatic endocrine cells from pluripotent stem cells. In previous studies by others, more than 2 weeks were necessary just to induce $\mathrm{PDX}^{+} /$ NKX6.1 ${ }^{+}$cells. We have previously reported differentiation methods for neurons [13], skeletal muscle cells [17], and lacrimal gland epithelium-like cells [15] in a short period of time by introducing synthetic mRNAs encoding specific transcription factors required for the target mature cells. In this study, we have attempted to shorten the period of time required for the induction of pancreatic endocrine cells from human pluripotent stem cells with the same differentiation method using PDX1 and NKX6.1 synthetic mRNAs. By introducing these transcription factors, it was possible to induce definitive endoderm and primitive gut tube marker-expressing cells within 3 days from hESCs.

Immunohistochemical examination confirmed the presence of pancreatic endocrine hormones such as insulin, glucagon, and somatostatin at day 13. Although most insulin-positive cells were glucagon-positive (double positive) and some of them were also somatostatin-positive (triple positive) cells, insulin-only-positive, monohormonal, so-called mature $\beta$ cells were present at as early as day 13. Previous studies have shown the expression of NKX6.1 is required for the development of the $\beta$ cell lineage from endocrine progenitors. Nostro et al. have identified the pathways that regulate the development of endocrine cells in vivo, and they found that NKX6.1 expression is a key factor to generate mature $\beta$ cells [20]. Our study may also indicate the importance of NKX6.1 $1^{+}$ expression for the development of monohormonal $\beta$ cell differentiation from human pluripotent stem cells.

This RNA-based differentiation method has advantages over others for potential therapeutic applications, since it is footprint-free and integration-free to the host genome. Thus, our method may be well suited to producing pancreatic endocrine cells from pluripotent stem cells for future regenerative therapies for diabetes.

\section{Conclusion}

By introducing synthetic mRNAs encoding two pancreatic transcription factors, PDX1 and NKX6.1 together with siPOU5F1, we were able to successfully establish a rapid and footprint-free protocol for differentiating pancreatic endocrine hormone-expressing cells from hESCs. With this protocol, HNF1B- and HNF4A-expressing primitive gut tubes were generated at day 3 , and pancreatic hormone-expressing cells such as insulin, glucagon, and somatostatin were generated at as early as day 13 .

\section{Funding}

This study was supported by JSPS KAKENHI Grant Number JP15H04812, JP16K15433 to SBHK, and the CREST program from the Japan Science and Technology Agency (JST) and the Research Center Network for Realization of Regenerative Medicine, Japan Agency for Medical Research and Development (AMED) to MSHK. This study was supported by the Keio University Medical Science Fund-The Mitsunada Sakaguchi Laboratory.

Availability of data and materials

Not applicable.

\section{Authors' contributions}

$\mathrm{HI}$ performed the experiments, analyzed the data, and wrote the manuscript. $T A, K l, S K G$, and $Y N$ supervised the experiments. NCN, SS, and HK performed the experiments. YY and MN supervised the study. MSHK discussed the data and edited the manuscript. SBHK conceived and supervised the study and wrote the manuscript. All authors read and approved the final manuscript.

\section{Authors' information}

Not applicable.

\section{Ethics approval and consent to participate}

All experiments were performed in accordance with the Guidelines for Derivation and Utilization of Human Embryonic Stem Cells by the Ministry of Education, Culture, Sports, Science, and Technology, Japan. Experimental protocols were approved by the Ethics Committee of Keio University School of Medicine for human stem cell experiments (No. 2012-01) and for recombinant DNA experiments (No. 24-010-12).

\section{Consent for publication}

Not applicable.

\section{Competing interests}

The authors declare that they have no competing interests.

\section{Publisher's Note}

Springer Nature remains neutral with regard to jurisdictional claims in published maps and institutional affiliations.

\section{Author details}

'Department of Systems Medicine, Keio University School of Medicine, 35 Shinanomachi, Shinjuku, Tokyo 160-8582, Japan. ${ }^{2}$ Division of Surgical Oncology, Department of Surgery, Nagoya University Graduate School of Medicine, Nagoya, Aichi, Japan.

Received: 7 May 2018 Revised: 10 September 2018

Accepted: 7 October 2018 Published online: 25 October 2018

\section{References}

1. Pagliuca FW, Millman JR, Gurtler M, Segel M, Van Dervort A, Ryu JH, Peterson QP, Greiner D, Melton DA. Generation of functional human pancreatic beta cells in vitro. Cell. 2014;159(2):428-39.

2. D'Amour KA, Bang AG, Eliazer S, Kelly OG, Agulnick AD, Smart NG, Moorman MA, Kroon E, Carpenter MK, Baetge EE. Production of pancreatic hormoneexpressing endocrine cells from human embryonic stem cells. Nat Biotechnol. 2006;24(11):1392-401.

3. Russ HA, Parent AV, Ringler JJ, Hennings TG, Nair GG, Shveygert M, Guo T, Puri S, Haataja L, Cirulli V, et al. Controlled induction of human pancreatic progenitors produces functional beta-like cells in vitro. EMBO J. 2015;34(13): 1759-72.

4. Toyoda T, Mae S, Tanaka H, Kondo Y, Funato M, Hosokawa Y, Sudo T, Kawaguchi Y, Osafune K. Cell aggregation optimizes the differentiation of human ESCS and iPSCs into pancreatic bud-like progenitor cells. Stem Cell Res. 2015;14(2):185-97.

5. Saxena P, Heng BC, Bai P, Folcher M, Zulewski H, Fussenegger M. A programmable synthetic lineage-control network that differentiates human IPSCs into glucose-sensitive insulin-secreting beta-like cells. Nat Commun. 2016;7:11247.

6. Rezania A, Bruin JE, Arora P, Rubin A, Batushansky I, Asadi A, O'Dwyer S, Quiskamp N, Mojibian M, Albrecht T, et al. Reversal of diabetes with insulin- 
producing cells derived in vitro from human pluripotent stem cells. Nat Biotechnol. 2014;32(11):1121-33.

7. Zhang D, Jiang W, Liu M, Sui X, Yin X, Chen S, Shi Y, Deng H. Highly efficient differentiation of human ES cells and iPS cells into mature pancreatic insulin-producing cells. Cell Res. 2009;19(4):429-38.

8. Offield MF, Jetton TL, Labosky PA, Ray M, Stein RW, Magnuson MA, Hogan BL, Wright CV. PDX-1 is required for pancreatic outgrowth and differentiation of the rostral duodenum. Development. 1996;122(3):983-95.

9. Schaffer AE, Freude KK, Nelson SB, Sander M. Nkx6 transcription factors and Ptfla function as antagonistic lineage determinants in multipotent pancreatic progenitors. Dev Cell. 2010;18(6):1022-9.

10. Basford CL, Prentice KJ, Hardy AB, Sarangi F, Micallef SJ, Li X, Guo Q, Elefanty AG, Stanley EG, Keller G, et al. The functional and molecular characterisation of human embryonic stem cell-derived insulin-positive cells compared with adult pancreatic beta cells. Diabetologia. 2012;55(2):358-71.

11. Sander M, Sussel L, Conners J, Scheel D, Kalamaras J, Dela Cruz F, Schwitzgebel V, Hayes-Jordan A, German M. Homeobox gene Nkx6.1 lies downstream of $\mathrm{Nk} \times 2.2$ in the major pathway of beta-cell formation in the pancreas. Development. 2000;127(24):5533-40.

12. Walczak MP, Drozd AM, Stoczynska-Fidelus E, Rieske P, Grzela DP. Directed differentiation of human iPSC into insulin producing cells is improved by induced expression of PDX1 and NKX6.1 factors in IPC progenitors. J Trans Med. 2016;14(1):341

13. Goparaju SK, Kohda K, Ibata K, Soma A, Nakatake Y, Akiyama T, Wakabayashi S, Matsushita M, Sakota M, Kimura H, et al. Rapid differentiation of human pluripotent stem cells into functional neurons by mRNAs encoding transcription factors. Sci Rep. 2017;7:42367.

14. Akiyama T, Wakabayashi S, Soma A, Sato S, Nakatake Y, Oda M, Murakami M, Sakota M, Chikazawa-Nohtomi N, Ko SB, et al. Transient ectopic expression of the histone demethylase JMJD3 accelerates the differentiation of human pluripotent stem cells. Development. 2016;143(20):3674-85.

15. Hirayama M, Ko SBH, Kawakita T, Akiyama T, Goparaju SK, Soma A, Nakatake Y, Sakota M, Chikazawa-Nohtomi N, Shimmura S, et al. Identification of transcription factors that promote the differentiation of human pluripotent stem cells into lacrimal gland epithelium-like cells. NPJ Aging Mech Dis. 2017;3:1.

16. Akiyama T, Wakabayashi S, Soma A, Sato S, Nakatake Y, Oda M, Murakami M, Sakota M, Chikazawa-Nohtomi N, Ko SBH, et al. Epigenetic manipulation facilitates the generation of skeletal muscle cells from pluripotent stem cells. Stem Cells Int. 2017:2017:7215010.

17. Akiyama T, Sato S, Chikazawa-Nohtomi N, Soma A, Kimura H, Wakabayashi S, Ko SBH, Ko MSH. Efficient differentiation of human pluripotent stem cells into skeletal muscle cells by combining RNA-based MYOD1-expression and POU5F1-silencing. Sci Rep. 2018:8(1):1189.

18. Akutsu H, Machida M, Kanzaki S, Sugawara T, Ohkura T, Nakamura N, Yamazaki-Inoue M, Miura T, Vemuri MC, Rao MS, et al. Xenogeneic-free defined conditions for derivation and expansion of human embryonic stem cells with mesenchymal stem cells. Regen Ther. 2015:1:18-29.

19. Warren L, Manos PD, Ahfeldt T, Loh YH, Li H, Lau F, Ebina W, Mandal PK, Smith ZD, Meissner A, et al. Highly efficient reprogramming to pluripotency and directed differentiation of human cells with synthetic modified mRNA. Cell Stem Cell. 2010;7(5):618-30.

20. Nostro MC, Sarangi F, Yang C, Holland A, Elefanty AG, Stanley EG, Greiner DL, Keller G. Efficient generation of NKX6-1+ pancreatic progenitors from multiple human pluripotent stem cell lines. Stem Cell Reports. 2015;4(4): 591-604.

Ready to submit your research? Choose BMC and benefit from:

- fast, convenient online submission

- thorough peer review by experienced researchers in your field

- rapid publication on acceptance

- support for research data, including large and complex data types

- gold Open Access which fosters wider collaboration and increased citations

- maximum visibility for your research: over $100 \mathrm{M}$ website views per year

At $\mathrm{BMC}$, research is always in progress.

Learn more biomedcentral.com/submissions 